\title{
Tratamento com corticosteroide de granuloma central de células gigantes mandibular em criança: relato de caso
}

\section{Treatment with corticosteroids for central giant cell granuloma of the mandible in a child: report of case}

\author{
Gabriela Caovila Felin* \\ Angélica Zanata* \\ Gabriel da Rocha* \\ Ferdinando De Conto** \\ Gisele Rovani** \\ Mateus Ericson Flores ${ }^{* * *}$
}

\section{Resumo}

O granuloma central de células gigantes (GCCG) é uma lesão óssea idiopática benigna incomum mais frequentemente encontrada em pacientes jovens do gênero feminino e na maioria dos casos acomete a mandíbula. Seu diagnóstico diferencial inclui outros neoplasmas osteolíticos dos maxilares. Objetivo: este artigo relata um caso de GCCG em paciente do gênero feminino, de 7 anos de idade, que procurou atendimento na Faculdade de Odontologia da Universidade de Passo Fundo (FOUPF), RS, Brasil. Relato de caso: o paciente apresentava aumento de volume na região de rebordo alveolar mandibular, ao longo dos últimos 2 meses, com gradual aumento de tamanho, e a tomografia computadorizada multiloculada, de limites bem definidos com expansão cortical. A paciente foi submetida à curetagem óssea da massa por acesso intraoral e acompanhada durante cinco anos. Considerações finais: o paciente não apresentou recidiva e o excelente resultado do tratamento de curetagem óssea, associada com injeção intralesional de corticoesteroide, mostrou-se como uma boa opção de abordagem conservadora.

Palavras-chave: Granuloma de células gigantes. Doenças estomatognáticas. Corticosteroides. Tumor ósseo.

\section{Introdução}

O granuloma central de células gigantes é uma lesão incomum representada por menos de $7 \%$ das lesões não neoplásicas dos maxilares. Caracterizado por ser uma lesão benigna, apresenta-se como uma lesão intraóssea formada por tecido fibroso com múltiplos focos de hemorragia, agregados de células gigantes multinucleadas e, ocasionalmente, trabéculas de tecido ósseo ${ }^{1}$.

A origem dessa lesão ainda é incerta. Acredita-se que essas lesões podem ter causas locais como traumas e hemorragia intraóssea, ou, ainda, causas sistêmicas que se relacionam a granuloma central de células gigantes, a síndromes como a Neurofibromatose I, à síndrome de Noonan e a distúrbios hormonais como hiperparatireoidismo e, também à gravidez. Acomete principalmente crianças e adultos jovens, sendo mais frequente em mulheres do que em homens e atingindo mais a mandíbula do que a maxila numa proporção de $2: 1^{2}$.

As lesões foram classificadas em agressivas e não agressivas, porém, não há diferenças histológicas entre essas. A forma não agressiva é mais comum e apresenta crescimento lento, bem delimita- 
do, assintomático e sem reabsorção radicular e perfuração das corticais. Entretanto, a forma agressiva apresenta um crescimento rápido, assintomático, assimetria da face e pode apresentar deslocamento de dentes, reabsorção radicular, expansão ou perfuração das corticais ósseas. Segundo relatos na literatura ${ }^{3,4}$, a recorrência da lesão é alta nas formas agressivas, principalmente em jovens, e a perfuração das corticais ósseas são encontradas predominantemente em maxila do que em mandíbula por ser um osso mais fino.

Histologicamente, a lesão agressiva apresenta, em uma área de superfície, maior quantidade de células gigantes. Quanto ao aspecto radiográfico, esse pode apresentar pequenas lesões radiolúcidas uniloculares ou extensas áreas radiolúcidas multiloculares, com margens bem definidas e expansão das corticais. Também, deslocamentos dentários e reabsorções radiculares podem ser encontrados. Entretanto, tais aspectos não são suficientes para o diagnóstico, podendo ser confundidos com outras lesões patológicas ${ }^{5}$.

A escolha do tratamento varia de acordo com a localização, o comportamento clínico, a extensão da lesão e, também, por conta dos fatores associados ao paciente, como a idade. $\mathrm{O}$ tratamento de eleição, para muitos autores, é a curetagem da lesão, sendo necessário, em alguns casos, osteotomia periférica, aplicação de laser ou crioterapia, e em lesões mais agressivas a ressecção em bloco. Essa lesão pode também ser tratada por abordagens não cirúrgicas como a injeção intralesional de corticóide, administração de doses diárias de calcitonina e de interferon alpha principalmente em pacientes jovens que apresentam lesões recorrentes ou extensas ${ }^{6-7}$.

O objetivo deste trabalho é relatar o caso clínico de granuloma central de células gigantes em paciente do gênero feminino, com 7 anos de idade, apresentando suas características clínicas e radiográficas e discutir sobre as formas de tratamento.

\section{Relato de caso}

Paciente do gênero feminino, de 7 anos de idade, buscou atendimento na Faculdade de Odontologia da Universidade de Passo Fundo (FOUPF) por aumento de volume na região de rebordo alveolar mandibular ao longo dos últimos dois meses com gradual aumento de tamanho, sem histórico de infecção ou traumatismo local prévio.

Ao exame clínico geral, não foram observados alterações da normalidade. Porém, ao exame físico intraoral, a paciente apresentou aumento de volume na região de rebordo alveolar inferior direito de cor violácea, de consistência dura e sem queixa de dor.

Os exames por imagens revelaram, na radiografia panorâmica e tomografia computadorizada, extensa imagem radiolúcida de $3,5 \mathrm{~cm}$, bem definida, expansiva, multiloculada, envolvendo o corpo da mandíbula e deslocando os dentes 43,44 e 45 para a base do corpo mandibular (Figuras 1A e 1B ).
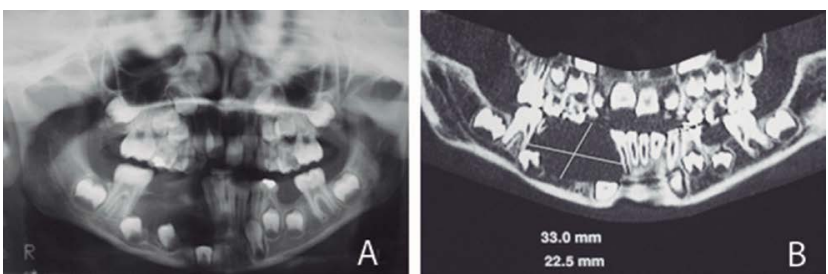

Fonte: imagens cedidas pelo autor Dr. Ferdinando de Conto.

Figura 1 - a) Radiografia panorâmica, apresentando lesão radilúcida multiloculada, com deslocamento dos elementos 43, 44 e 45. b) Tomografia computadorizada, mostrando a lesão com $33.0 \mathrm{~mm}$ de extensão, com 22,5mm de altura, envolvendo a cortical vestibular

Exames de dosagem de cálcio, fosfatase alcalina e paratormônio estavam normais e diminuíram significativamente a hipótese clínica de diagnóstico de tumor marrom do hiperparatireoidismo.

Por se tratar de uma criança e ter forte hipótese clínica de GCCG, foi optado por uma única abordagem cirúrgica, sob anestesia geral, em caráter de biopsia excisional. O material curetado, de aspecto granulomatoso e de cor violácea, foi enviado para análise histopatológica, que revelou múltiplas células gigantes multinucleadas, distribuídas em um córion rico em macrófagos, contendo ainda áreas hemorrágicas, neocapilares e presença de hemossiderina, confirmando a hipótese clínica (Figura 2).

Foi realizado tratamento cirúrgico, de forma conservadora, com curetagem óssea local, por acesso intraoral e todos os dentes permanentes foram mantidos (Figuras 3A e B). A associação de injeção intralesional de corticoide tipo Decadron $10 \mathrm{mg}$, semanalmente, sob anestesia local, foi realizada durante seis semanas.

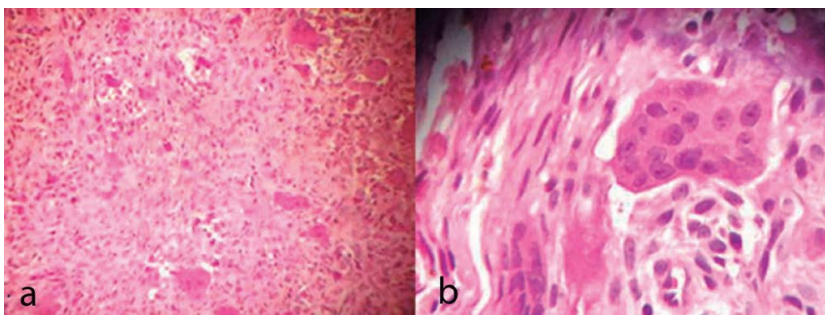

Fonte: imagens cedidas pelo laboratório de patologia do Instituto de Ciências Biológicas da Universidade de Passo Fundo.

Figura 2 - a) HE: dimensão 100 x. O campo mostra inúmeras células gigantes multinucleadas distribuídas em um córion rico em macrófagos, contendo ainda áreas hemorrágicas. b) HE: dimensão de 400x. Célula gigante multinucleada acompanhada de macrófagos livres no tecido conjuntivo, neocapilares e presença de hemossiderina
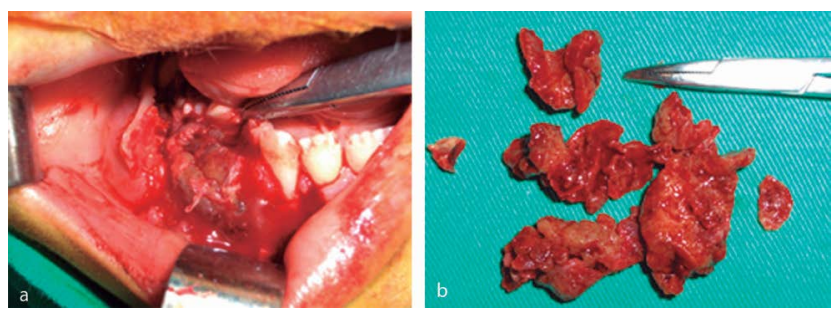

Fonte: imagens cedidas pelo autor Dr. Ferdinando de Conto.

Figura 3 - a) Aspecto transoperatório da lesão em região de corpo de mandíbula; b) Material coletado de aspecto granulomatoso avermelhado 
Após dois anos de acompanhamento clínico e radiográfico foi detectado o surgimento de pequena área radiolúcida na região em que havia a lesão, apesar de ter evoluído positivamente para o movimento de erupção dos dentes que estavam envolvidos (Figura 4). Esse princípio de recidiva foi tratado somente com aplicação de mais uma sequencia de Decadron e apresentou remissão espontânea. Passados cinco anos, a paciente não apresentou recidiva e a oclusão foi estabelecida a partir de terapia ortodôntica, que foi instituída durante este período (Figuras 5A e B).

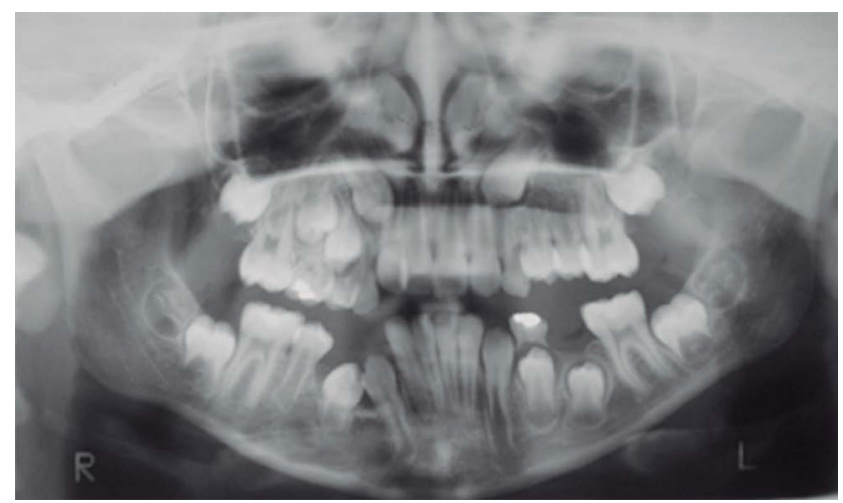

Fonte: imagem cedida pelo autor Dr. Ferdinando de Conto.

Figura 4 - Controle radiográfico de dois anos pós-operatório evidenciando movimento eruptivo dos dentes 43, 44 e 45 e imagem sugestiva de recidiva entre os dentes 43 e 44

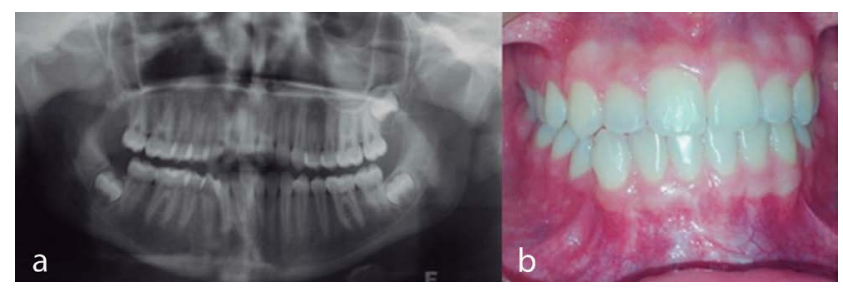

Fonte: imagens cedidas pelo autor Dr. Ferdinando de Conto.

Figura 5 - a) Pós-operatório de seis anos com exame de imagem revelando ausência de recidiva; b) Oclusão dentária satisfatória

\section{Discussão}

Por ser uma lesão pouco comum, o GCCG apresenta controvérsias no que diz respeito à sua natureza. Jaffe, em 1953, sugeriu o termo granuloma de células gigantes reparador, diferenciando-a do tumor de células gigantes que apresentava diferenças clínicas e histológicas. A inflamação, o trauma e a hemorragia intramedular podem ser a etiologia dessa lesão ${ }^{8}$.

Considerada uma lesão benigna, de bom prognóstico e intraóssea, tem origem mesenquimal e é caracterizada por células gigantes multinucleadas, com tamanho e núcleo variáveis, distribuídas pelo tecido fibroso celular que contém múltiplos focos de hemorragia e, frequentemente, tecido osteoide e trabeculado de osso imaturo na periferia da lesão. Quando comparado ao TCG, são relatadas, na literatura, a diferença no tamanho e no número de núcleos de células gigantes, em que no TCG há a presença de células gigantes de maiores dimensões com núcleos mais numerosos?.

O GCCG é mais frequente na mandíbula do que na maxila, sendo mais encontrado na região anterior. Quando acomete a maxila pode invadir o soalho do seio maxilar ou da órbita e, também, as fossas nasais. Quando acometido na mandíbula, pode causar expansão e perfuração das corticais ${ }^{10} . E$ É mais frequente nas primeiras três décadas de vida e o gênero feminino é mais susceptível do que o gênero masculino. Essa patologia ocorre em menos de $7 \%$ de todas as lesões não neoplásicas dos maxilares. No caso relatado, a paciente era do sexo feminino, com apenas 7 anos de idade, confirmando o que a literatura menciona.

Seu diagnóstico diferencial deve ser realizado com o tumor marrom do hiperparatireoidismo, com o cisto ósseo aneurismático, com o TCG e com a displasia fibrosa. É importante realizar exames de cálcio, fósforo, fosfatase alcalina e paratormônio para excluir o diagnóstico de hiperparatireoidismo, pois as suas características histológicas e radiográficas são semelhantes ${ }^{11}$. A paciente relatada apresentou todos os exames com níveis normais, excluindo-se essa hipótese diagnóstica.

O tratamento de escolha, mais comumente utilizado, é a curetagem por apresentar baixo grau de recorrência e facilidade de execução. Contudo, em alguns casos, tal procedimento pode ser complementado com uma osteotomia periférica, aplicação de laser ou crioterapia na loja cirúrgica para diminuir as taxas de recidivas. Em lesões mais agressivas, nas quais há a perfuração da cortical e o envolvimento dos tecidos moles, pode ser necessária a ressecção em bloco ${ }^{3,12}$.

Um estudo, de 2006, avaliou informações de 26 pacientes com GCCG, sendo dez desses agressivos. A maioria dos casos foram tratados com enucleação ou curetagem (cinco casos) ou curetagem com osteotomia periférica (vinte casos), e apenas um caso foi necessário a ressecção em bloco. Três casos, dentre as lesões agressivas, apresentaram recidiva. No estudo, não foi relatado o uso de outro tratamento não cirúrgico, porém citaram a calcitonina como uma boa alternativa à cirurgia ${ }^{1}$. Outro estudo, em 2005 , mostrou 83 pacientes com GCCG, sendo dezesseis de forma agressiva. $O$ tratamento de escolha em oitenta casos foi a curetagem cirúrgica e em três foi a calcitonina humana. No grupo tratado cirurgicamente, 21 pacientes apresentaram recidiva. Entretanto, os três pacientes tratados com calcitonina e que apresentaram lesões mais agressivas, com deslocamento dentário, não demonstraram nenhuma recidiva, podendo ser uma boa alternativa para cirurgia ${ }^{13}$. Já em 2007, foi relatado o caso de um paciente com uma lesão em palato duro, com $2 \mathrm{~cm}$ de tamanho, no qual foi realizado a sua curetagem. Após 15 meses, não foram relatados índices de recidiva. 
Quando uma lesão agressiva acomete crianças e adultos jovens essa ressecção pode levar a grandes defeitos na face e a perda de dentes, o que pode acarretar na criança problemas funcionais, estéticos e psicológicos, sendo, então, necessário analisar outros tipos de tratamento. Injeção intralesional de corticosteroides, aplicação de calcitonina e interferon alpha podem ser associadas à curetagem ${ }^{4}$.

$\mathrm{Na}$ literatura, alguns estudos clínicos, com uso da calcitonina no tratamento dessas lesões, têm mostrado resultados positivos de remissão da lesão sem recidiva. Acredita-se que é devido ao controle da osteoclastogênese, uma vez que apresenta efeito de inibição direto sobre osteoclastos e é empregada no tratamento de condições patológicas como a doença de Paget e em algumas metástases ósseas ${ }^{14,2}$.

Outro medicamento utilizado como adjuvante, citado na literatura, é o interferon alpha, um agente com ação antiangiogênica utilizado no tratamento de hemangiomas e tumores vasculares. Devido às suas propriedades, espera-se uma involução da lesão, conduzindo a hipótese de que o GCCG responda a essa terapia ${ }^{5}$. Um estudo retrospectivo do ano de 2007 relatou uma amostra de 26 casos de TCG agressivos, nos quais, além da enucleação da lesão, era administrado interferon alpha subcutânea e o resultado foi positivo, sem referência de recidivas ${ }^{15}$. Entretanto, na literatura ainda existem poucos relatos de casos bem documentados publicados sobre o uso de interferon alpha em combinação com curetagem cirúrgica como um tratamento para GCCG agressivos $^{5}$.

Na literatura, são citados dois estudos que utilizaram bifosfonatos para o tratamento de GCCG como um tratamento primário ou adjuvante em pacientes adultos. Por serem compostos insolúveis, ligam-se à hidroxiapatita e suprimem a reabsorção óssea e a diferenciação osteoclástica, e, em doses elevadas, podem inibir o crescimento de hidroxiapatita. Esses também são utilizados no tratamento da osteoporose, hipercalcemia de malignidade, doença de Paget e várias metástases ósseas. Porém, essa substância não deve ser utilizada em crianças, pois pode predispor o desenvolvimento de raquitismo e persistir no esqueleto por anos mesmo após cessado o tratamento ${ }^{2,4}$.

Todavia, a injeção intralesional com corticoide tem sido bem relatada por diversos autores principalmente quando realizada em pacientes jovens, evitando que estruturas vitais sejam comprometidas e diminuindo a chance de grandes deformidades faciais. Sua principal vantagem é de ser uma técnica simples. Tal técnica estimula a proliferação e a diferenciação de precursores de osteoclastos e cessa a reabsorção óssea por meio da inibição da produção extracelular de proteases lisossomais e da ação apoptótica de células semelhantes a osteoclastos. De acordo com um estudo em 2005, é realizado injeções semanais de Triamcinolona $10 \mathrm{mg} / \mathrm{ml}$ associada à lidocaína a $0,5 \%$ (partes iguais), numa dose de $2 \mathrm{ml}$ de solução para cada $2 \mathrm{~cm}$ de radiolucidez, em lugares distintos da lesão, por no mínimo seis semanas. Há a evidência de que a formação óssea começa a aparecer após três meses de uso. Pacientes com diabetes mellitus, úlcera péptica, infecção e sistemas imunológicos comprometidos apresentam contraindicação para esse tipo de tratamento ${ }^{2}$.

Um estudo de Calicut, Kerala India, relatou o caso de uma paciente de 17 anos, com edema na região do mento e mobilidade no primeiro molar e segundo pré-molar inferior esquerdo. A radiografia apresentou uma lesão multilocular que se estendia desde a região parassínfise direito à segunda região molar esquerda da mandíbula. Havia, também, uma imagem radiolúcida à direita na área de molares. Após a biopsia confirmar GCCG, foi realizado o tratamento com triamcinolona $10 \mathrm{mg} / \mathrm{ml}$ associada à lidocaína a $0,5 \%$ e injetado na lesão. Aproximadamente $2 \mathrm{ml}$ da solução foi injetada em cada $2 \mathrm{~cm}$ da lesão. O tratamento foi realizado durante seis semanas e após três meses já foram observados regeneração óssea. $\mathrm{O}$ método descrito foi escolhido por oferecer a preservação das estruturas vitais, evitando um defeito grave em uma paciente jovem, além de ser uma técnica simples e barata ${ }^{16}$.

Um outro estudo realizado na Faculdade de Odontologia da Universidade Federal do Ceará relatou 21 casos de GCCG tratados com injeção intralesional de corticosteroides, com idade entre 5 anos e 25 anos. Foi utilizado o protocolo do uso de $20 \mathrm{mg} / \mathrm{ml}$ de hexacetonido de triamcinolona diluídos em solução anestésica de lidocaína $2 \%$ / epinefrina 1:200,000 em proporção de 1:1; 1,0 ml de solução foi infiltrada em cada área de $1 \mathrm{~cm}^{3}$ radiolúcida da lesão, totalizando seis semanas de aplicação. Entre os casos, dez pacientes apresentaram lesões agressivas e onze deles lesões do tipo não agressivas. Apenas dois pacientes mostraram respostas negativas ao tratamento e foi necessário a ressecção cirúrgica. Por meio desse resultado, os autores observaram que antes de optar por uma cirurgia radical, deve-se considerar o uso dessa técnica ${ }^{17}$.

Um recente trabalho relatou o caso clínico de uma criança com um GCCG em mandíbula tratado favoravelmente com injeções de corticoide intralesional e período de acompanhamento de cinco anos ${ }^{7}$. Com base nesse tipo de relato, acredita-se que esse tratamento é uma boa escolha para essa lesão por se tratar de um método simples, de fácil execução e com a preservação das estruturas anatômicas, evitando deformidades faciais severas.

A etiopatogenia dessa lesão deve ser melhor esclarecida e pesquisada para que, assim, os resultados de tratamento sejam sempre positivos. No caso relatado, considerando a idade da paciente e a extensão da lesão, foi optado por uma curetagem da lesão, de forma conservadora, com a opção de preservação de todos os dentes permanentes envolvidos devido ao uso de injeção intralesional de corticosteroide, por um período de seis semanas, 
bem como ao rigoroso e periódico controle clínico e radiográfico. Essa técnica é uma excelente opção de tratamento, especialmente em crianças e adultos jovens, em comparação com os efeitos da cirurgia sobre o crescimento dos ossos da face e, também, traz menos danos aos dentes adjacentes.

\section{Considerações finais}

Conforme muitos autores relatam, o uso de corticosteroides como uma abordagem terapêutica alternativa no tratamento dessa lesão tem mostrado resultados positivos. A reparação total das estruturas ósseas que são afetadas são observadas na maioria dos casos, devido ao fato de invadir tecidos mínimos, diminuindo as chances de causar grandes defeitos ósseos. A curetagem cirúrgica, associada ao uso de corticosteroide, é uma terapia bastante eficaz para GCCG em pacientes jovens e crianças com lesões agressivas, revelando-se essa uma boa alternativa, inclusive para evitar procedimento cirúrgico radical ou desnecessário para crianças em desenvolvimento esquelético.

\section{Abstract}

The Central giant cell granuloma (CGCG) is an uncommon idiopathic benign intraosseous lesion, most frequently found in young women, and most cases occur in the mandible. Its diagnosis includes other maxillary osteolytic neoplasms. Objective: this article reports a CGCG case in a 7-year-old female patient, seeking care services at the School of Dentistry, in the University of Passo Fundo (FOUPF), RS, Brazil. Case report: the patient presented a swelling in the mandibular alveolar ridge area over the past 2 months, with gradual size increase. A CT scan showed multilocular lesion, with well-defined limits, and cortical expansion. The patient underwent intraoral osseous curettage of the mass, and was followed-up for 5 years. Final considerations: the patient did not present recurrence and the excellent result of osseous curettage treatment with intralesional injections of corticosteroids proved to be a satisfactory option of conservative approach.

Keywords: Giant Cell Granuloma. Stomatognathic Diseases. Corticosteroids. Bone Tumor.

\section{Referências}

1. Kruse-Lösler B, Diallo R, Gaertner C, Mischke KL, Joos U, Kleinheinz J. Central giant cell granuloma of the jaws: a clinical, radiologic, and histopatholic study of 26 cases. Oral Surg Oral Med Oral Pathol Oral Radiol Endod. 2006; 101(3): 346-54.

2. Gomes ACA, Marchiori EC, Oliveira Filho, LB, Porto GG. Tratamento do granuloma central de células gigantes. Rev. Cir. Traumatol. Buco-Maxilo-Fac. 2005; 5(2): 9-18.

3. Gunel C, Erpek G, Meteoglu I. Giant cell reparative granuloma in the hard palate. Int. J. Pediatr. Otorhinolaryngol, 2007; 2: 76-9.
4. Schütz MD, El-Bassuoni KH, Munish J, Hamed HH, Padwa BL. Aggressive central giant cell granuloma of the mandible. J Oral Maxillofac Surg. 2010; 68(10):2537-44.

5. De Lange J, Akker HPVD, Berg HVD. Central giant cell granuloma of the jaw: a review of the literature with emphasis on therapy options. Oral Surg Oral Med Oral Pathol Oral Radiol Endod. 2007; 104(5): 603-12.

6. Ünal M, Karabacak T, Vayisoğlu Y, Bağis HE, Pata YS, Akbas Y. Central giant cell reparative granuloma of the mandible caused by a molar tooth extraction: Special reference to the manuever of drilling the surgical field. Int. J. Pediatr. Otorhinolaryngol 2006; 70: 745-8.

7. Goyal P, Narula R, Bansal S, Bansal S, Garg P. Conservative nonsurgical treatment of mandibular central giant cell granuloma in an adolescente: a case report. Pediatric Dental Journal, Pediatric Dental Journal (2014). [citado 2014 jun. 1] Disponível em URL: http://dx.doi.org/10.1016/j. pdj.2013.12.002.

8. Reddy V, Saxena S, Aggarwal P, Sharma P, Reddy M. Incidence of central giant cell granuloma of the jaws with clinical and histological confirmation: an archival study in Northern India. Br J Oral Maxillofac Surg. 2012; 668-72.

9. Luna AHB. Avaliação retrospectiva do tratamento do granuloma central de células gigantes pela área de cirurgia buco-maxilo-facial da Faculdade de Odontologia de Piracicaba entre 1996 a 2006 [Tese de Doutorado]. Piracicaba: Faculdade de Odontologia de Piracicaba da Unicamp; 2006.

10. Gomes ACA, Silva EDO, Porto GG, Machiori E. Granuloma central de células gigantes: relato de caso. Rev. Cir. Traumatol. Buco-Maxilo-Fac. 2004; 4(2):91-5.

11. Üstündağ E, Iseri M, Keskin G, Müezzinoğlu B. Central giant cell granuloma. Int. J. Pediatr. Otorhinolaryngol., 2002; 65: $143-8$.

12. Theologie-Lygidakis $\mathrm{N}$, Telona P, Michai-IStrantzia C, Iatrou I. Treatment of central giant-cell granulomas of the jaws in children. J Craniomaxillofac Surg, 2011; 39: 639-44.

13. De Lange J, Akker HPVD. Clinical and radiological features of central giant-cell lesions of the jaw. Oral Surg Oral Med Oral Pathol Oral Radiol Endod, 2005; 104(5): 464-70.

14. Pogrel MA, Regezi, JA, Harris S, Goldring SR. Calcitonin treatment for central giant cell granulomas of the mandible: report of two cases. J Oral Maxillofac Surg, 1999; 57: 848-53.

15. Kaban LB, Troulis MJ, Wilkinson MJ, Ebb, Dodson TB. Adjuvant antiangiogenic therapy for giant cell tumors of the jaws. J Oral Maxillofac Surg, 2010; 65(10): 2018-23.

16. Rajeevan NS, Soumithran CS. Intralesional corticosteroid injection for central giant cell granuloma. A case report. lnt. J. Oral Maxillofac. Surg., 1998; 27: 303-4.

17. Nogueira RLM, Teixeira RC, Calvacante RB, Ribeiro RA, Rabenhosrt SHB. Intralesional injection of triamcinolone hexacetonide as na alternative tretment for central giantcell granuloma in 21 cases. Int. J. Oral Maxillofac. Surg., 2010; 39(12): 1204-10. 